\title{
Effect of lipopolysaccharide (LPS) on HAEC cells. Does nicotinamide N- methyltranferase sensitize HAEC cells to LPS?
}

\author{
Oksana Stępińska $^{1}$, Dorota Dymkowska ${ }^{1 *}$, Łukasz Mateuszuk $^{2}$, Krzysztof Zabłocki $^{1 *}$ \\ ${ }^{1}$ Laboratory of Cellular Metabolism, Nencki Institute of Experimental Biology, PAS \\ 3 Pasteura Str., 02-093 Warsaw, Poland \\ 2 Jagiellonian Centre for Experimental Therapeutics (JCET), Jagiellonian University, \\ 14 Bobrzynskiego Str., 30-348 Krakow, Poland \\ * Corresponding authors, senior researchers
}

Correponding address: Nencki Institute of Experimental Biology, 3 Pasteura Str., 02-093

Warsaw, Poland. k.zablocki@nencki,edu.pl; d.dymkowska@nencki.edu.pl

Key words: Endothelial cells, lipopolysacharide Mitochondria, nicotinamide N-methyltransferase,.

Running title: LPS increases NNMT level in endothelial cells

\begin{abstract}
Treatment of endothelial cells with bacterial lipopolysaccharide (LPS) evokes a number of metabolic and functional consequences which built a multifaceted physiological response of endothelium to bacterial infection. Here effects of LPS on human aortic endothelial cells (HAEC) have been investigated. Among the spectrum of biochemical changes substantially elevated N-nicotinamide methyltransferase (NNMT) protein level was particularly intriguing. It has been shown that silencing of the NNMT-encoding gene prevented several changes which are observed in control HAECs due to treatment with LPS. They include significantly increased cytosolic $\mathrm{Ca}^{2+}$ concentration and abnormally strong calcium response to thapsigargin, altered energy metabolism which is switched to anaerobic glycolysis and rearrangement of the mitochondrial network organization. Biochemical mechanisms behind protecting effect of partial NNMT deficiency remains unknown but we speculate that the primary role in this phenomenon is attributed to normalized $\mathrm{Ca}^{2+}$ response in cells partially deprived of the NNMT gene. However, this assumption needs to be verified experimentally. Nevertheless, this paper focuses the reader's attention on NNMT, which is an important enzyme that potentially may affect cellular metabolism by two means: direct influence based on a regulation of $\mathrm{NAD}^{+}$ synthesis through modulation of nicotinamide availability, and a regulation of $\mathrm{S}$ adenosylmethionine concentration and therefore controlling of methylation processes including modification of chromatin and epigenetic effects.
\end{abstract}

\section{Introduction}

Endothelial cells are directly exposed to many physiological and pathological factors transported in the blood. Bacterial lipopolysaccharides (LPS) belongs to the latter category. 
They form a family of large molecules containing three structural elements: a core oligosaccharide, an O-antigen, and a lipid A component [Bertani and Ruiz, 2018; Farhana and Khan, 2021; Whitfield et al., 2020]. LPS is an endotoxin produced by gram-negative bacteria which is neutralized under normal conditions by the innate immune system. This involves activation of intracellular signalling pathways which are initiated by activation of TLR4 receptors, evolutionarily conserved proteins which are responsible for recognizing bacteriaderived infections and form the first line of defending them. High LPS levels have certain toxic effects on cells, whereas low LPS levels promote cell proliferation. In sepsis cellular response to LPS is enormously strong and results in a generalized progressive inflammatory response [For rev. Fock and Parnova, 2021]. Epidemiological studies have indicated that LPS constitute a risk factor for diseases such as atherosclerosis and diabetes [Chao et al., 2017]. Inflammatory and immunological responses of endothelial cells stimulated with LPS have been broadly investigated. It has been found that LPS not only activates endothelial cells indirectly through inflammatory mediators, such as tumour necrosis factor $\alpha(\mathrm{TNF} \alpha)$, interleukin-1 $\beta$ (IL-1 $\beta$ ), interferons (IFNs) and others, from macrophages and immune cells [Gabarin et al., 2021; Meng and Lowell, 1997] but also directly influencing these cells stimulating vasodilatation due to increasing NO generation [Chang et al., 2000]. Moreover, LPS increases endothelial permeability and leads to endothelial barrier dysfunction [Schlegel et al., 2009]. Intensive studies on endothelium were mostly focused on a development of new therapeutic strategies as endothelial impairments are behind cardiovascular diseases and are a cause of excessive mortality in western countries in particular. On the other hand, cellular bioenergetics and the regulation of intermediary metabolic processes in endothelial cells are still unclear. It is commonly accepted that endothelial energy metabolism relies mostly on glycolytic ADP phosphorylation while the major mitochondrial role is to regulate intracellular calcium signalling and reactive oxygen species formation [Szewczyk A et al., 2015]. However, in pathological conditions, metabolic relations and the contribution of particular processes to global cellular metabolism may be changed. Investigating biochemical mechanisms responsible for endothelial response to various stimuli may be helpful to a better understanding of pathological processes and finding new therapeutic approaches.

Our previously published data convincingly show that challenging of endothelial cells with TNFa or palmitate affects mitochondrial network architecture and stimulates mitochondrial biogenesis that was interpreted as a pro-survival response to the stimuli applied at a relatively low concentration insufficient to induction of acute cell death [Drabarek et al., 2012; Dymkowska et al., 2017]. Furthermore, we found an incubation of endothelial cells with statins results in cellular stress response which was accompanied by an elevation of nicotinamide-N-methyl transferase (NNMT) [Dymkowska et al., 2021]. This enzyme catalyzes methyl group transfer from S-adenosylmethionine (SAM) to nicotinamide (NA). Reduction of NNMT gene expression was found to increase detrimental effect of menadione. In turn, an activation of NNMT/SIRT1 patways seems to have a protective effect increasing survival rate of endothelial cells in oxidative stress [Campagna et al. 2021] Methylnicotinamide (MNA) is known as a modulator of several physiological functions of endothelium because of antiinflammatory and anti-thrombotic properties [Bartus et al., 2008; Chlopicki et al., 2007; Mateuszuk et al. 2020]. 
MNA was also found to have vasodilatory properties as it stimulates NO formation. Moreover, it has a multifaceted positive effect on lipid metabolism and storage, as well as lipoprotein and PGI2 levels [Nejebati et al., 2018]. Manifold effects of MNA on endothelial cells has recently been described in a comprehensive review [Begum et al. 2021].

Methylation of NA might potentially reduce its availability for $\mathrm{NAD}^{+}$synthesis via the salvage pathway and therefore affect cellular redox processes. Moreover, reduced availability of $\mathrm{NAD}^{+}$could limit sirtuins-catalyzed deacetylation of many substrates including acetylated histones. Furthermore, an excessive NNMT activation may reduce SAM availability for other reactions and influence various methylation processes. Both events may have epigenetic consequences and influence gene expression due to affected chromatin modifications. Thus NNMT acts at a junction between direct acute metabolic regulation and modified gene expression. Interestingly, overexpression of the NNMT gene in SH-SY5Y neuroblastoma cells significantly increased expression of sirtuins 1, 2 and 3 encoding genes and a role of sirtuins 3 as a protein mediating effect of NNMT on the respiratory complex I was postulate. NNMT is expressed in a variety of tissues and organs and an elevated amount of this enzyme was found in many pathologies. Among them Parkinson disease (neurons), cirrhosis (liver), pulmonary disorders and various cancers [Roessler et al., 2005; Tomida et al., 2008; Sternak et al., 2010; Kim et al., 2010; Emanuelli et al., 2010; For rev see

Roberti et al., 2021]

In view of all aforementioned facts changes in cellular NNMT content and activity may be triggered in diverse pathological conditions and have very complex metabolic and physiological consequences concerning a broad spectrum of cellular functions. Therefore, the holistic depicting of the role of NNMT seems to be very puzzling. Our previous experiments on energy metabolism of vascular endothelium were done with the use of immortalised human endothelial cells, EA.hy926. Here we have switched our interest to the primary human aortic endothelial cells (HAEC) and their metabolic response to bacterial lipopolysaccharide. We have focused our attention on the effects of LPS on mitochondria, intermediary energy metabolism and the putative role of NNMT in the cellular response to this lipopolysaccharide. We have found that incubation of HAEC cells with LPS substantially increases NNMT protein level and silencing of the NNMT-encoding gene modifies and mostly alleviates some other cellular changes which appeared as a response to the LPS treatment. However, we have not confirmed an expected link between an elevated NNMT level and cellular $\mathrm{NAD}^{+}$content. Thus, in this study, we have pointed out the role of NNMT in the endothelial response to LPS while molecular mechanisms behind these effects need further study to be fully elucidated.

\section{$\underline{\text { Material and Methods }}$}

\section{Cell culture and treatment}

Human Aortic Endothelial Cells (HAEC) derived from two the same age male donors were purchased from Lonza. Cells were grown in Endothelial Cell Growth Medium BulletKit ${ }^{\circledR}-2$ (EGM-2 BulletKit, Lonza) at $37^{\circ} \mathrm{C}$ in the atmosphere of $5 \% \mathrm{CO}_{2}$ and $95 \%$ air. The culture medium was supplemented with conveniently packaged as single-use aliquots called SingleQuots, containing: human recombinant epidermal growth factor, human fibroblast growth factor, vascular endothelial growth factor, ascorbic acid, hydrocortisone, human 
recombinant insulin-like growth factor, heparin, $2 \%$ foetal bovine serum and gentamicin with amphotericin (Lonza). Cells were passaged every three days. Confluent cells were exposed to 100 ng/ml LPS (Escherichia coli O111:B4, List Biological Laboratories, \#421) for a period between $0.5 \mathrm{~h}$ to $24 \mathrm{~h}$, as indicated in figure legends. In all experiments, cells of the third passage were used

\section{NNMT gene silencing}

The cells were cultured for 24 hours before starting the silencing procedure. A freshly prepared mixture of NNMT specific siRNA (Ambion, ThermoFisher Scientific, \#4390826) and jetPrime transfection reagent (PolyPlus transfection) was added to the confluent cells for 24 hours. Then the silencing solution was replaced with a fresh culture medium and incubated for another 24 hours before further treatment with LPS. The scrambled siRNA (Ambion, ThermoFisher Scientific, \#4390847) was used as a control. The efficiency of NNMT gene silencing was determined by the Western Blot technique.

\section{Cell lysis, and Western Blot analysis}

Cell lysates were prepared as previously described [Drabarek et al., 2012; Dymkowska et al., 2014]. Proteins were separated by polyacrylamide gel electrophoresis (PAGE) under denaturing conditions in the presence of $0.1 \%$ sodium dodecyl sulphate (SDS, BioShop) [Laemmli, 1970]. After transferring to PVDF membrane (Millipore) proteins of interest were detected with the use of specific primary antibodies: NNMT (Santa Cruz Biotechnology sc376048); Mitochondrial Dynamics Antibody Sampler Kit (Cell Signaling Technology); ICAM1 (Santa Cruz Biotechnology sc-8439); VCAM-1 (Santa Cruz Biotechnology sc-13160); $\mathrm{Cu} / \mathrm{Zn}-\mathrm{SOD}$ (Santa Cruz Biotechnology sc-11407); Nox4 (Santa Cruz Biotechnology sc30141); MnSOD (BD Transduction Laboratories 611581); Autophagy Antibody Sampler Kit (Cell Signaling Technology); Sirt1 (Cell Signaling Technology 9475); Sirt3 (Cell Signaling Technology 5490); Nrf1 (Santa Cruz Biotechnology sc-515360); Nrf2 p(Ser ${ }^{40}$ ) (Abcam ab75026); $\beta$-actin-peroxidase (Sigma). Anti-rabbit and anti-mouse secondary antibodies conjugated with horseradish peroxidase (HRP) were obtained from Abcam. For HRP detection (Fusion FX, Vilber Lourmat) chemiluminescent substrate Immobilon Classico (Merck Millipore) was used. The optical density of bands corresponding to defined proteins was determined densitometrically with the BIO-1D software (Vilber Lourmat) and expressed in relation to $\beta$-actin used as a loading control.

\section{Immunocytochemistry}

For visualization of the mitochondrial network architecture, confluent cells grown on the collagen-coated coverslips $(\phi 12 \mathrm{~mm})$ were loaded with $100 \mathrm{nM}$ MitoTracker Red CMXRos (Molecular Probes) as previously described [Dymkowska et al., 2021]. After gentle rinsing, the cells were fixed with $4 \%$ paraformaldehyde, rinsed with PBS supplemented with 5\% BSA, permeabilized with $0.1 \%$ Triton in 5\% BSA and rinsed overnight with $1 \%$ BSA containing PBS at $4^{\circ} \mathrm{C}$. Finally cells were stained with Actin-Stain 488 Phalloidin (1:1000; Cytoskeleton) and with $2 \mu \mathrm{g} / \mathrm{ml}$ Hoechst 33342 (ThermoFisher Scientific) Finally, cells were sealed in 
VECTASHIELD Mounting Medium (VECTOR Laboratories). Fluorescence microscopy analysis was carried out using Zeiss Spinning Disc microscope.

\section{Mitochondrial mass}

Total mitochondrial mass (amount of mitochondria) in confluent HAEC cells was measured fluorimetrically with MitoTracker ${ }^{\circledR}$ Green (Invitrogen M7514) as described previously [Drabarek et al., 2012; Dymkowska et al., 2017]. Fluorescence was measured at 490 $\mathrm{nm}$ and $530 \mathrm{~nm}$ wavelengths for the excitation and the emission, respectively, using a microplate reader Infinite M1000 Pro reader (Tecan). Results were expressed per mg of protein.

\section{Reactive Oxygen Species assay}

In all protocols, fluorescence was measured using Infinite M1000 Pro Microplate Reader (Tecan) and results were expressed per mg protein.

Measurement of cytosolic ROS level. Cells were loaded with a $5 \mu \mathrm{M}$ DHE probe (dihydroethidium, Molecular Probes) as described previously [Dymkowska et al., 2021]. The fluorescence was measured at the excitation and emission wavelengths of $535 \mathrm{~nm}$ and $610 \mathrm{~nm}$, respectively.

Measurement of the relative amounts of ROS in cells. Cells were loaded with $10 \mu \mathrm{M}$ DFF probe solution (2 ', 7' -difluoro-dihydrofluorescein, Invitrogen) as described previously [Drabarek et al., 2012; Dymkowska et al., 2014]. Fluorescence was measured without washing at excitation $485 \mathrm{~nm}$ and emission $520 \mathrm{~nm}$.

Measurement of mitochondrial ROS. Cells were loaded with $5 \mu \mathrm{M}$ MitoSOX Red probe solution (2-hydroxymitoethidium, Invitrogen), carefully rinsed and fluorescence was measured at excitation $510 \mathrm{~nm}$ and emission $580 \mathrm{~nm}$.

\section{Metabolite determination using HPLC method}

To measure glycolytic intermediates, TCA metabolites and adenine nucleotide intracellular content the cells were rinsed with cold $0.3 \mathrm{M}$ mannitol. Then cells monolayers were extracted with the mixture composed of methanol: acetonitrile: water (2:2:1). The extracts were collected and centrifuged at $4{ }^{\circ} \mathrm{C}$. The supernatants were stored at $-80{ }^{\circ} \mathrm{C}$ for further procedures. Pellets were stored for protein measurement. Before metabolite assay to each sample 140 pmoles of the appropriate standard was added and then selected metabolites were separated and quantitively analyzed with the use of ion-exchange chromatography system (Dionex ICS-3000 chromatograph, Thermo Fisher Scientific Inc.) coupled with Waters ZQ mass spectrometer (Waters Corporation). Metabolite separation was performed on AS11-HC high-capacity anion-exchange column using 1-80 $\mathrm{mM} \mathrm{KOH}$ gradient as the solvent. In the case of ATP, ADP and AMP measurements, an integrated with Dionex chromatograph UV-detector $(260 \mathrm{~nm})$ was used. All samples were measured three times and results were quantified both to the reference standard and amount of cell protein and presented as a mean of replicates. 
To determine the extracellular methyl nicotinamide (MNA) level $100 \mu 1$ of culture medium was collected from each dish and frozen at $-80^{\circ} \mathrm{C}$. Cell monolayers were rinsed with PBS, trypsinized and centrifuged. The pellets were stored for protein measurement. Aliquots of $50 \mu \mathrm{l}$ of defrosted medium were spiked with $5 \mu \mathrm{l}$ of internal standard (deuterated analogues of the analyte) at the concentration of $25 \mu \mathrm{g} / \mathrm{ml}$. Samples were subjected to deproteinization with $100 \mu \mathrm{l}$ of acetonitrile acidified with $0.1 \%$ formic acid), vortexed, cooled at $4^{\circ} \mathrm{C}$ for $15 \mathrm{~min}$ and centrifuged $\left(15000 \mathrm{x} \mathrm{g}, 15 \mathrm{~min}, 4^{\circ} \mathrm{C}\right)$. Supernatants were injected into the LC column. Chromatographic analysis was performed using an UltiMate 3000 LC system (Thermo Scientific Dionex, Sunnyvale, CA) consisting of a pump (DGP 3600RS), a column compartment (TCC 3000RS), an autosampler (WPS-3000TRS), and an SRD-3600 solvent rack (degasser). Chromatographic separation was carried out on an Aquasil C18 analytical column (4.6 mm x $150 \mathrm{~mm}, 5 \mathrm{~mm}$; Thermo Scientific). MNA was eluted with the mobile phase consisting of acetonitrile (A) and $5 \mathrm{mM}$ ammonium formate (B) in isocratic elution (80:20 v/v) at the flow rate of $0.8 \mathrm{ml} / \mathrm{min}$. MNA detection was performed with the use of a TSQ Quantum Ultra mass spectrometer equipped with a heated electrospray ionization interface (HESI-II Probe) (Thermo Scientific, Waltham, MA, US). The mass spectrometer was operating in the positive ionisation using selected reactions monitoring mode (SRM), monitoring the transition of the protonated molecular ions (for MNA Precursor $[\mathrm{m} / \mathrm{z}]=137$, Product $[\mathrm{m} / \mathrm{z}]=94$ ). Data acquisition and processing were accomplished using Xcalibur 2.1 software.

To measure cellular $\mathrm{NAD}^{+}$content the cells were rinsed with cold PBS and then extracted with an ice-cold 10\% solution of perchloric acid. Then the cells were harvested, transferred to Eppendorf tubes, forced through the thin needle, vortexed and incubated on ice for 15 minutes. Then, lysates were centrifuged at $15000 \mathrm{x}$ g at $4^{\circ} \mathrm{C}$ for $5 \mathrm{~min}$. The supernatants were carefully transferred to fresh tubes and neutralized with $3 \mathrm{M}$ potassium carbonate and centrifuged again at $15000 \mathrm{x}$ g at $4^{\circ} \mathrm{C}$ for $5 \mathrm{~min}$. Supernatants were transferred to fresh tubes and stored at $-80^{\circ} \mathrm{C}$. NAD ${ }^{+}$measurements were made according to the method described by Yoshino and Imai [2013].

\section{Calcium measurement}

Cytosolic $\mathrm{Ca}^{2+}$ concentration was measured with the fluorescent probe Fura-2/AM. Cells grown on coverslips previously coated with collagen I (Sigma) were loaded with $2 \mu \mathrm{M}$ Fura-2/AM in the culture medium for $30 \mathrm{~min}$ at $37^{\circ} \mathrm{C}$ in darkness. The cells were then washed twice with the solution composed of $5 \mathrm{mM} \mathrm{KCl}, 1 \mathrm{mM} \mathrm{MgCl} 2,0.5 \mathrm{mM} \mathrm{Na} 2 \mathrm{HPO}_{4}, 25 \mathrm{mM}$ HEPES, $130 \mathrm{mM} \mathrm{NaCl}, 1 \mathrm{mM}$ pyruvate, $5 \mathrm{mM}$ D-glucose, and $0.1 \mathrm{mM} \mathrm{CaCl}_{2}, \mathrm{pH} 7.4$ and the coverslips were mounted in a cuvette containing $3 \mathrm{ml}$ of either the nominally $\mathrm{Ca}^{2+}$-free assay solution (as above but $0.1 \mathrm{mM} \mathrm{CaCl}_{2}$ was replaced by $0.05 \mathrm{mM}$ EGTA). The fluorescence was measured at room temperature in a Hitachi F-7000 fluorimeter set in the ratio mode at 340 $\mathrm{nm} / 380 \mathrm{~nm}$ excitation and $510 \mathrm{~nm}$ emission wavelengths. At the end of each experiment the Fura 2 fluorescence was calibrated by addition of $8 \mu \mathrm{M}$ ionomycin to determine maximal fluorescence followed by the addition of EGTA to complete removal of Ca2 [Zabłocki et al. 2005].

\section{Oxygen consumption}


HAEC cells were grown in Seahorse XF96 polystyrene tissue culture plates (SeahorseBioscience Europe) and stimulated with LPS upon reaching confluence. Before measurement, cells were incubated in Seahorse XF DMEM assay medium (without phenol red and Sodium Bicarbonate) containing $10 \mathrm{mM}$ glucose, $1 \mathrm{mM}$ pyruvate and $2 \mathrm{mM}$ glutamine in a non- $\mathrm{CO}_{2}$ incubator at $37^{\circ} \mathrm{C}$ for $1 \mathrm{~h}$. Oxygen consumption rate (OCR) was measured every 3 min with a mixing of 3 min in each cycle, with 4 cycles per step using of Seahorse XFe96 Analyzer (Agilent). Cell Mito Stress Test was used for assessing mitochondrial function. The sequential addition of oligomycin A $(1.5 \mu \mathrm{M})$, FCCP $(1.0 \mu \mathrm{M})$, antimycin A/rotenone $(0.5 \mu \mathrm{M})$ dissolved in DMEM assay medium allowed for the calculation of OCR linked to ATP production, maximal respiration capacity and spare respiratory capacity. Basal respiration was measured prior to injection of oligomycin A. Finally, the data were normalized according to the total protein content in each well.

\section{Expression of the results}

The results are presented as means of ratios of treatment (experimental group) to control values \pm SD for the number of separate experiments. Statistical significance of differences ( $p$ values less than 0.05) was calculated using a one-way analysis of variance (ANOVA). Proper Multiple Range Tests was used for comparisons between experimental groups.

\section{Results}

\section{Response of control HAECs to LPS}

In all experiments, LPS was used at a concentration of $100 \mathrm{ng} / \mathrm{ml}$. It was the lowest one that was found to induce cellular response expressed as an elevation of the adhesion molecules level. HAECs incubated with LPS for 6 and $24 \mathrm{~h}$ exhibit time-dependent changes in the protein level of both adhesive molecules tested (Fig. 1). ICAM protein content gradually increases during cell incubation with LPS while VCAM protein level is 30-fold elevated (averagely with poor reproducibility) after 6-hour-treatment and recovers to the still increased but only by 2.5fold in comparison to untreated cells after 24 hours after addition of LPS to the growth medium.

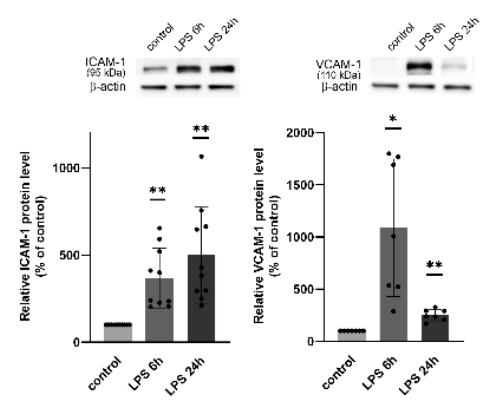

Fig. 1. Effect of LPS on adhesive molecule proteins level in HAEC cells. Each bar indicates mean values $\pm S . D$ of the relative change of tested parameter vs. untreated control cells assumed as 100\%. $n=7-10, * p<0.05 ; * * p<0,005$. Above bar plots, a corresponding western blot from the representative experiment is shown. 
Under the same conditions, cells did not exhibit any symptoms of reduced viability (not shown), while elevated HO-1, Cox2 and manganese superoxide dismutase levels suggest a cellular oxidative-stress response (Fig. 2).

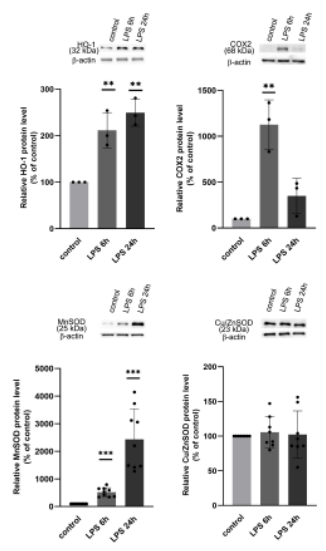

Fig. 2. Effect of LPS on proteins involved in cellular stress response and antioxidative defence. Each bar indicates mean values \pm S.D of the relative change of tested parameter vs. untreated control cells assumed as 100\%. n=3-9, **p <0.005; ***p<0,0005. Above bar plots, a corresponding western blot from the representative experiment is shown.

The whole set of aforementioned results is original for HAECs, but in fact, confirm previously published experimental data obtained with the use of various cells and dispersed amongst a number of papers [Dayang et al., 2019; Menden et a;., 2013; Sampath et al., 2009].

Fluorescent microscopy analysis indicates transient changes in the architecture of the mitochondrial network upon treatment of HAEC cells with LPS. Mitochondria evenly dispersed within control cells became more condensed in the perinuclear space in the $6^{\text {th }}$ hour after the addition of LPS into the growth medium while an architecture of mitochondrial network observed after an additional $18 \mathrm{~h}$ seems to be substantially recovered (Fig. 3).

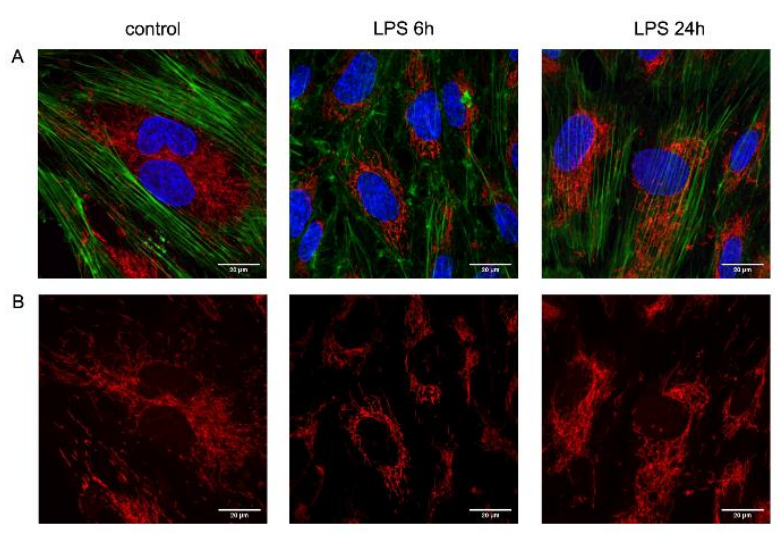


Fig. 3. Effect of LPS on mitochondrial network organization. Green-actin cytoskeleton stained with Acti-stain 488 phalloidin, Red-mitochondria labelled withMitoTracker CMXRos, Blue - nucleus with Hoechst 33342.

These changes are accompanied by LPS-induced alterations in the efficiency of the oxidative phosphorylation

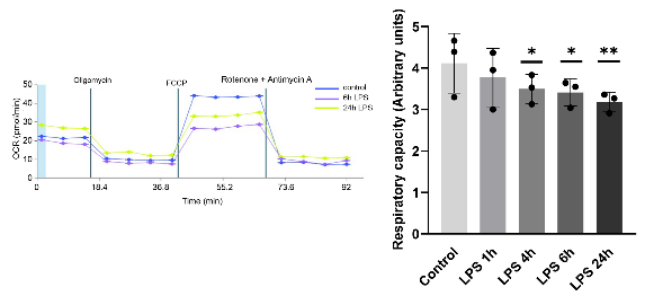

Fig. 4. Effect of LPS on the oxygen consumption rate of HAECs. Row data obtained during direct oxygen consumption (representative experiment) and mitochondrial respiratory capacity of control and LPS-treated with LPS. Mean value \pm S.D for $n=3, * p<0.05$, **p<0.005.

Fig. 4 A shows representative traces obtained with the use of the Agilent Seahorse FX analyzer. Although at this stage of the experiment the traces are not normalized to protein level they may be considered reliable as the cells were always seeded at the same density and the experiments were performed after the monolayer had reached complete confluency. Thus the number of cells in each well may be assumed as the same with satisfying approximation. Fig. 4B indicates reduced respiratory chain capability, which represents the fraction of the respiratory chain activity presumably attributed to covering energy demand for ADP phosphorylation. Changes in oxidative phosphorylation are accompanied by appropriate changes in other metabolic processes involved in cellular energetics. Cross-over analysis of glycolytic and tricarboxylic acids cycle (TCA) metabolites clearly indicates transient inhibition of pyruvate kinase followed by complete recovery and reversed ratio between PEP and pyruvate. (Fig. 5).
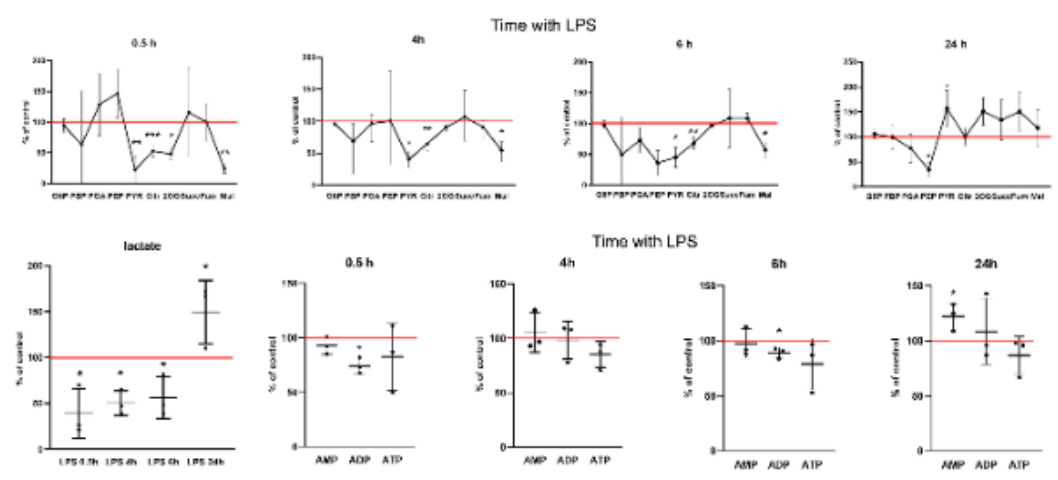

Fig. 5. Effect of LPS on the relative metabolite and adenine nucleotide content. Cross-over graphs show mean values $\pm S$.D of the relative change of tested parameter vs. untreated control cells assumed as $100 \%$ (red line). $n=3, * P<0.05, * * p<0.005, * * * p<0,0005$.

These changes meet a substantial increase in the lactate formation which follows a significant drop of its concentration shortly after the addition of LPS to the HAECs culture. Also huge cross-over effect between PEP and pyruvate apparently indicates a reduced flow 
between PEP and pyruvate at the beginning of treatment with LPS and subsequent reversal of this proportion suggests an elevation of pyruvate kinase activity. Additionally such a change may coincide with an inhibition of the further steps of the TCA cycle and therefore an accelerated consumption of pyruvate by lactate dehydrogenase. Effects of LPS on the adenine nucleotide content seem to be statistically insignificant though it exhibits the same tendency after 4, 6 and $24 \mathrm{~h}$ of the treatment. Thus some decrease in ATP level should be considered as potentially relevant. Presumably, the gradual reduction of the respiratory chain activity is a cause of an excessive accumulation of TCA cycle intermediates. Finally, endothelial metabolism became more glycolytic but still efficient to deliver an ample amount of ATP.

Furthermore, LPS affects cellular calcium homeostasis, here visualized as the changed intensity of $\mathrm{Ca}^{2+}$ response along the whole procedure preceding and following thapsigargininitiated activation of the store-operated calcium entry.

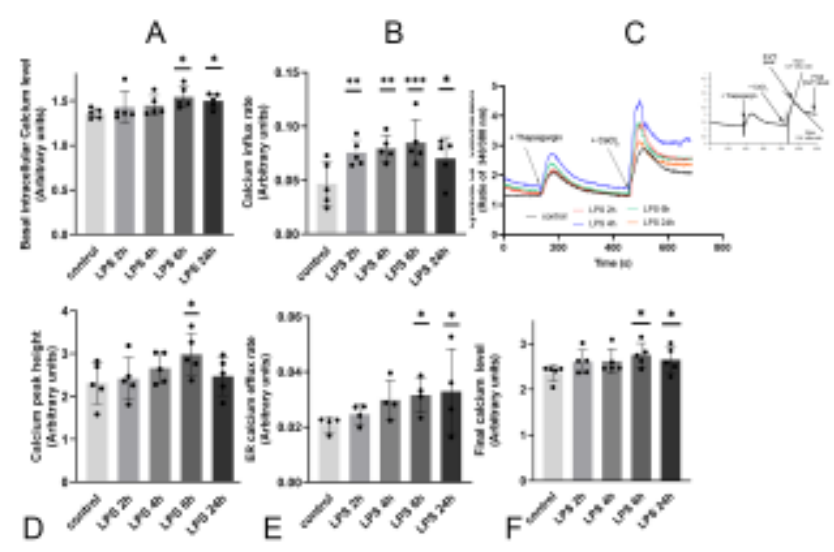

Fig. 6 Effect of LPS on cellular calcium response. Relative changes in the cytosolic $\mathrm{Ca}^{2+}$ concentration were estimated with the use of Fura 2-AM fluorescent probe and expressed in arbitral units as differences between fluorescent ratios as described in the Material and Methods chapter. Bars represent mean values $\pm S D$ for $n$ 4-5 experiments. A Basal $\left[\mathrm{Ca}^{2+}\right] c$ prior to addition thapsigargin. B Slopes after addition of $\mathrm{CaCl}_{2}$ reflect rates of $\left[\mathrm{Ca}^{2+}\right] \mathrm{c}$ elevation due to activated store-operated calcium entry. $C$ Representative traces and a scheme explaining how particular parameters were calculated. $\mathrm{D}\left[\mathrm{Ca}^{2+}\right] c$ peak heights were calculated as a difference between maximal $\left[\mathrm{Ca}^{2+}\right] \mathrm{c}$ and $\left[\mathrm{Ca}^{2+}\right] \mathrm{c}$ immediately before the addition of $\mathrm{CaCl}_{2} . \mathbf{E}$ Calcium efflux rate is reflected by the slope of a post-peak reduction of $\left[\mathrm{Ca}^{2+}\right] \mathrm{c} . \boldsymbol{D}$ Final $\left[\mathrm{Ca}^{2+}\right] \mathrm{c}$ level is shown as a difference between fluorescence ratio on the last plateau and that established immediately before addition of $\mathrm{CaCl}_{2}$ to the assay. In the presence of ionomycin in the assay $\mathrm{Ca}^{2+}$ influx is very fast and uncontrolled, thus efficiency of $\mathrm{Ca}^{2+}$ extrusion is a key factor influencing the cytosolic $\mathrm{Ca}^{2+}$ concentration value at the newly established steady-state that depends on the relative velocities of $\mathrm{Ca}^{2+}$ entry and removal. 


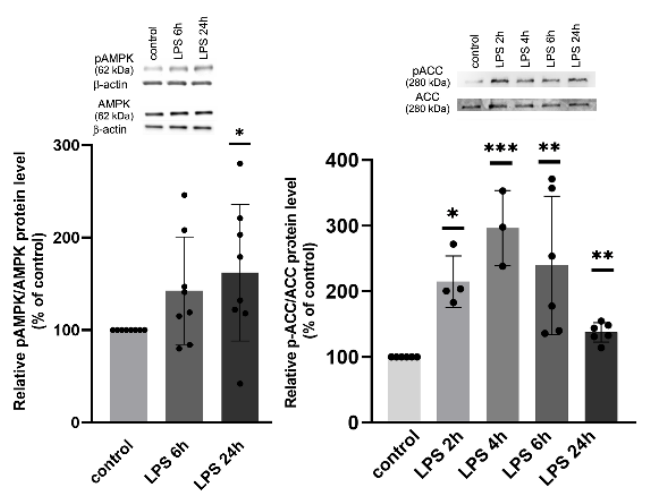

Fig. 7. Effect of LPS on AMPK and ACC proteins content. Each bar indicates mean values \pm $S . D$ of the relative change of tested parameter vs. untreated control cells assumed as $100 \%$. $n=3-8, * p<0.05 ; * * p<0.005$, ***p<0.0005. Above each set of bars, a corresponding western blot from the representative experiment is shown.

The increase in the cytosolic $\mathrm{Ca}^{2+}$ concentration may to some extent explain an increased fraction of phosphorylated and therefore activated AMP-activated protein kinase (AMPK). Increased proportion of phosphorylated acetyl-CoA carboxylase (p-ACC) indicates elevated AMPK activity although temporal patterns of these effects are not closely parallel. Transient activation of AMPK suggests a metabolic shift toward ATP-delivering catabolic processes though reduced oxidative phosphorylation efficiency is not in line with such an assumption.

Keeping in mind earlier findings published by other authors [Akar et al., 2020] and results obtained in our laboratory [Dymkowska et al., 2021] indicating that some pathological stimuli may elevate NNMT content in a variety of cells and that activity of this enzyme may be related to cellular energy metabolism [Mistry et al., 2020] we tested the putative effect of LPS on NNMT level in HAECs (Fig. 8).

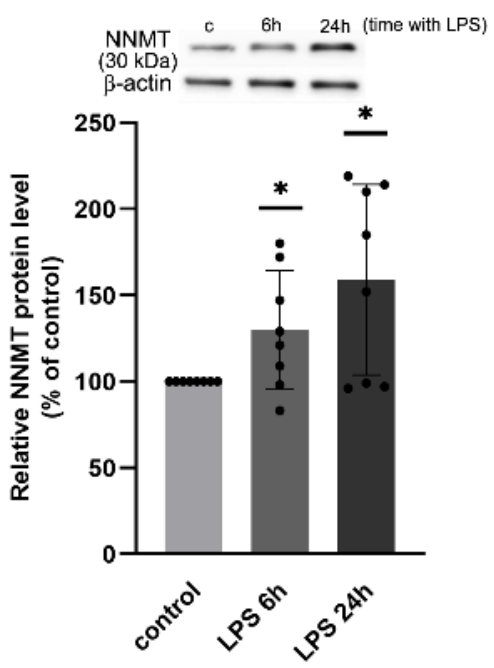

Fig. 8. LPS increases NNMT level. Bars show relative data from 7 independent experiments. NNMT protein level was assumed to be $100 \%$. Data shown as Mean $\pm S D, * p<0.05$. Above the bars western blot from one experiment is shown. 
Despite these changes, the amount of MNA released from cells treated with LPS to the extracellular milieu is much lower than that in the case of untreated HAECs (Fig 10 C. compare the first bars in the each set of three). It shows that NNMT western-blot data do not correspond with NNMT activity at least estimated on basis of extracellular MNA level. However, this partially transient effect on MNA level is not accompanied by any changes in $\mathrm{NAD}^{+}$content (data not shown). To test whether LPS-induced increase in the NNMT level is of any importance for cellular metabolic response to this lipopolysaccharide or is unrelated to these effects, HAEC cells with silenced NNMT-encoding gene were used.
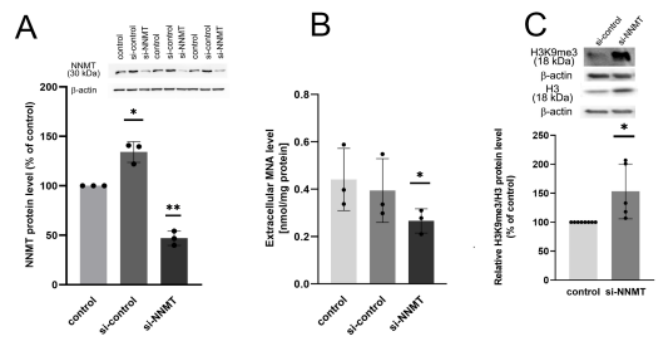

Fig. 9. Silencing of the NNMT-encoding gene and its effects on MNA generation and histone H3 methylation. NNMT and H3K9me3 were detected with Western blot after the addition of siRNA, representative Western blot shown above a graph. Data shown as mean $\pm S D, n=3-8$; $* p<0.05, * * p<0.005$.

An incubation of HAECs with silenced NNMT-encoding gene but without LPS increases the degree of histone H3 methylation (Fig. 9) and reduced extracellular MNA content. Fig. $10 \mathrm{~A}$ shows that a reduction of the NNMT protein was observed as soon as after $30 \mathrm{~min}$ of incubation with siRNA and this substantial effect persisted at least for 24 hours.

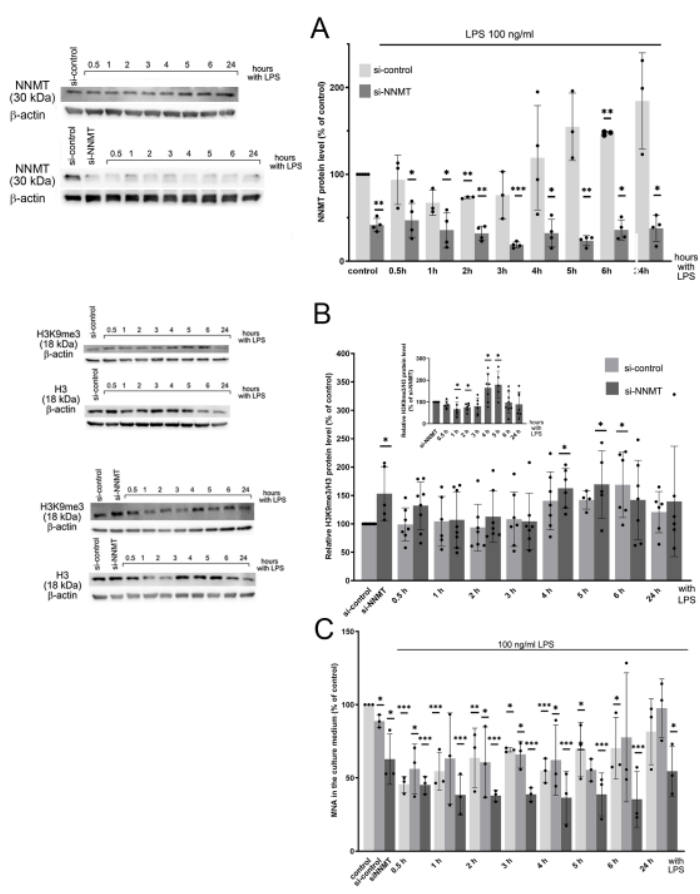


Fig. 10. Effect of LPS on NNMT level, histone H3 methylation and MNA content in HAEC cells with silenced NNMT gene. Each bar indicates mean values \pm S.D of the relative change of tested parameter vs. untreated control cells assumed as 100\%. $n=3-8, * p<0.05 ; * * p<0.005$, $* * * p<0.0005$. In the left column, acorresponding western blots from the representative experiments are shown.

LPS does not influence a residual amount of NNMT protein which is detectable in cells with silenced NNMT encoding gene. Similarly, LPS does not elevate MNA level in cells incubated with scrambled RNA, despite the increased amount of NNMT protein. Interestingly, silencing of the NNMT gene did not aggravate decreasing effect of LPS on MNA level (Fig. $10 \mathrm{C}$ ) while the degree of histone $\mathrm{H} 3$ methylation was somewhat increased (Fig. $10 \mathrm{~B}$ ). It allows concluding that LPS reduces NNMT activity despite the elevation of NNMT protein content thus slight stimulation of SAM-dependent methylation processes is reasonable.

\section{Response of HAECS with silenced NNMT gene to LPS}

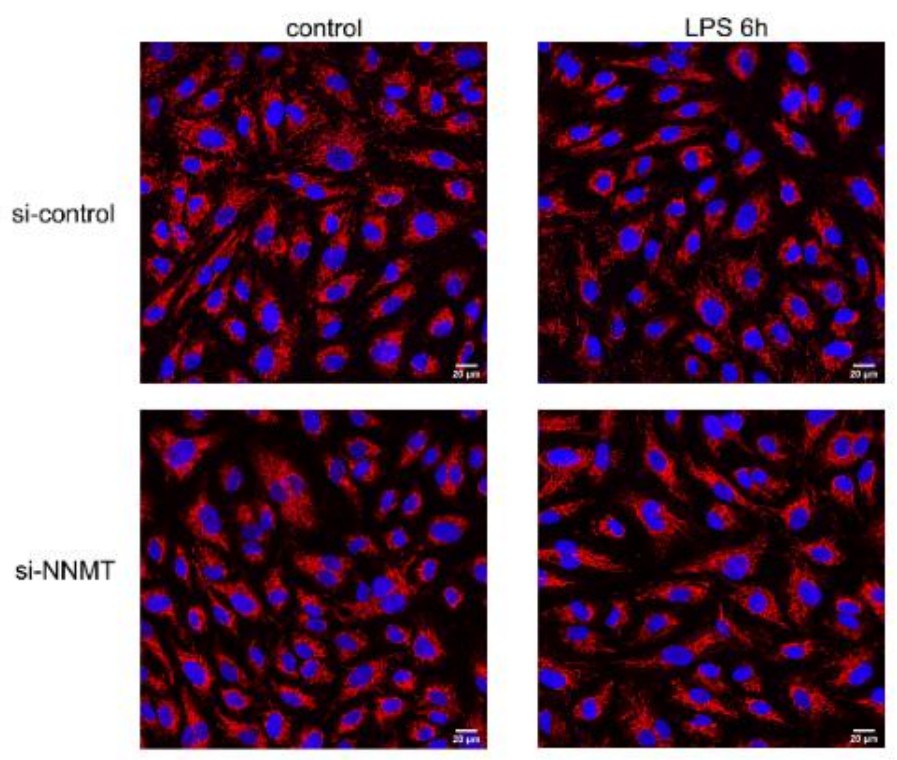

Fig. 11. Effect of LPS on the mitochondrial network in HAEC cells with silenced NNMTencoding gene. Red - mitochondria labelled with Mitotracker CMXRos, blue - nucleus with Hoechst 3334

Fig. 11 shows how LPS induces changes in the mitochondrial network architecture in HAECs cells partially depleted of NNMT due to siRNA treatment and in the equivalent control cells. A comparison of these two populations indicates that silencing of the NNMT-encoding gene weakened LPS-increased tendency of the mitochondrial network to be positioned more perinuclearly than in the case of control cells (see Fig. 3) or incubated with the scrambled RNA (Fig. 11).

Moreover, Western blot data show that the treatment of cells with unaffected NNMT gene expression (scrambled control for siRNA) with LPS resulted in a substantial increase in Mfn1 and Opa1 proteins at least up to the sixth hour of the exposition while prolonged treatment up to $24 \mathrm{~h}$ results in substantial reduction of Mnf1 content. Silencing of the NNMT gene prevented these changes (Fig. 12). Furthermore, treatment of NNMT-deficient cells with LPS 
for 4 hours and longer reduces Mfn1 content. In cells pre-incubated with the scrambled equivalent of siRNA Mnf2 level was unaffected upon treatment with LPS but increased in cells with silenced NNMT gene. However, this stimulatory effect persisted no longer than for $1 \mathrm{~h}$ of treatment with this lipopolysaccharide (Fig. 12).

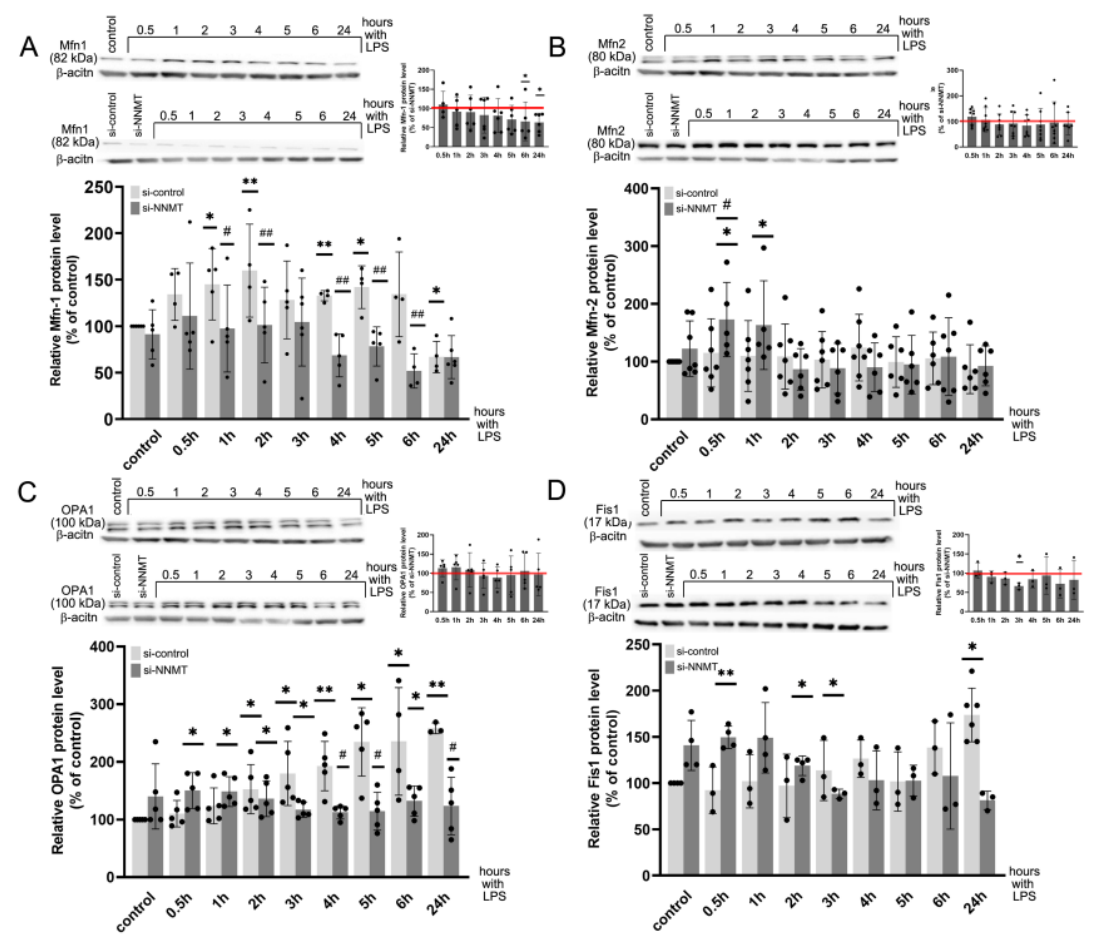

Fig. 12. Effect of LPS and NNMT-gene silencing on the level of proteins involved in the mitochondrial fusion and fission processes. A. Mfn1, B. Mfn2, C. OPA1 and D. Fis1. In each pair of bars the first one represents a relative effect of LPS in cells with unaffected NNMT gene (cells treated with scrambled RNA) vs the same cells but without the treatment with LPS. The second bar shows a relative effect of LPS in cells with silenced NNMT encoding gene vs. the same cells but without the treatment with LPS. An appropriate protein level in cells incubated with scrambled RNA and not treated with LPS was assumed as 100. Small inserts next to each western blot represent a relative effect of LPS in cells with silenced NNMT encoding gene vs. effect of LPS in cells pretreated with scrambled RNA and assumed to be 100 for each time point separately. $n=4-7, * p<0.05 ; * * p<0.005$, vs si-control; \#p<0.05, \#\#<0.005 vs LPS in control cells. Above each set of bars, a corresponding western blot from the representative experiment is shown.

Interestingly, an elevation of Fis1 protein level in control cells is only observed after the prolonged exposition of cells to LPS while in cells with silenced NNMT gene, Fis1 level increases during the first three hours of the treatment with LPS. Thus, the modification of mitochondrial network architecture shown in Fig. 11 and changes in the level of proteins directly involved in the fission-fusion processes upon treatment of cells with LPS seem to be correlated with NNMT protein content in HAECs. Moreover, they also are accompanied by seriously affected metabolite profiles. 
A

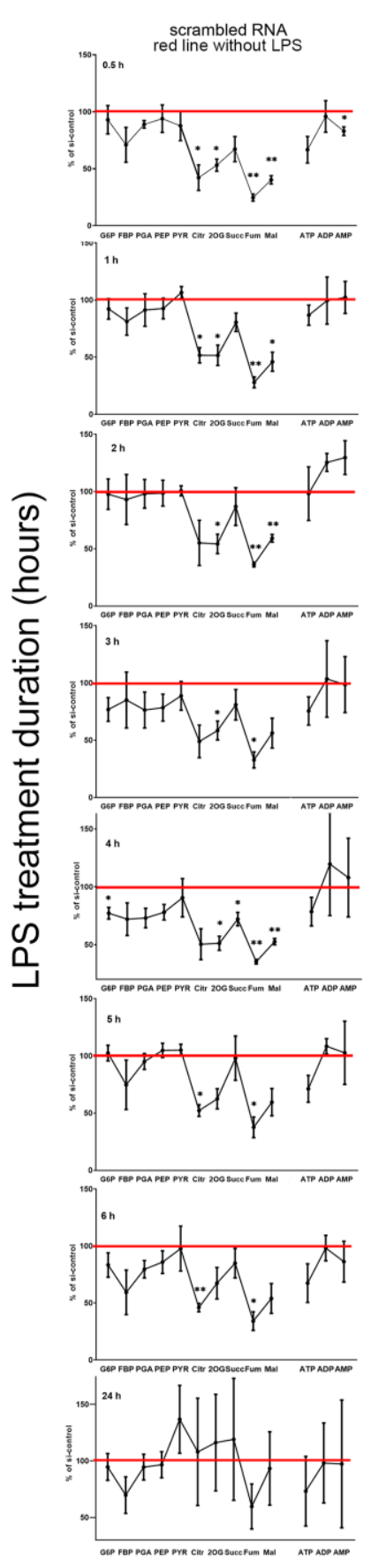

B
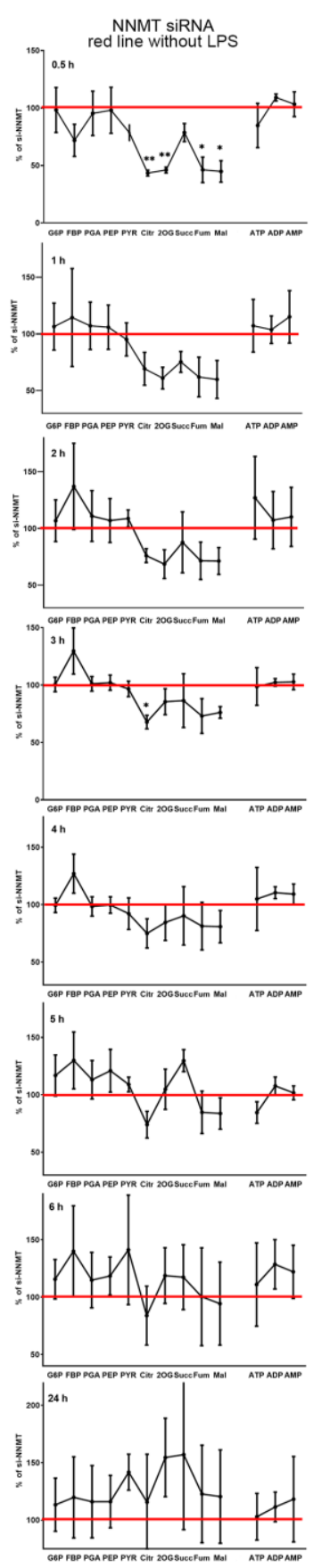

C

NNMT siRNA with LPS ${ }_{150}$ vs. scrabled RNA without LPS
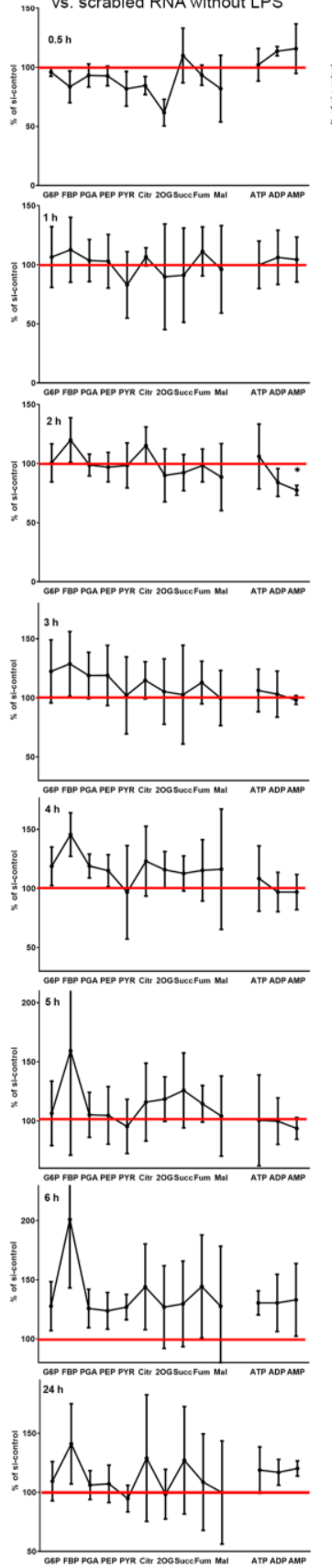

Metabolite abbreviations

G6P - glucose-6-phosphate
FBP - fructose-1,6-bisphosphate
PGA - 3-phosphoglycerate

PEP - phosphoenolpyruvate

Pyr - pyruvate

$2 \mathrm{OG}$ - 2-oxoglutarate Succ - succinate
Fum - fumarate Fum - fumarate
Mal - malate

silenced NNMT vs. scrambled (red line) without LPS

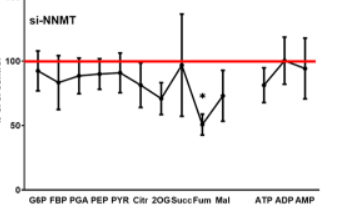

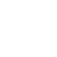

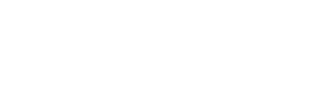

Fig. 13. Effect of LPS and NNMT gene silencing on glycolytic and Krebs cycle metabolite content in HAEC cells. Column A: Effect of LPS on cells treated with scrambled RNA vs. without LPS; Column B: Effect of LPS on cells treated with siRNA (silenced NNMT gene) vs. without LPS. Column C: Effect of NNMT gene silencing plus LPS vs. cells treated with scrambled RNA without LPS. $n=3$, *p<0.05, **p<0.005.

The LPS-evoked effect on the relative metabolite content in HAEC cells is visibly weakened in cells with silenced NNMT-encoding gene. As shown in Fig. 12 column A, LPS substantially reduces the level of most of the metabolites involved in glycolysis and the Krebs cycle in cells with unaffected NNMT gene expression (scrambled RNA) while this effect is less 
profound in cells with silenced NNMT (Fig. 12 column B). Fig. $12 \mathrm{C}$ clearly shows that silencing of NNMT encoding gene diminishes or reverses effects of LPS visualised in Fig. 12 A. It is noteworthy that LPS does not affect $\mathrm{NAD}^{+}$level under any experimental conditions applied (not shown), indicating that the availability of this dinucleotide is not a limiting factor that could control glycolysis and TCA. In other words silencing of the NNMT gene accelerates recovery of metabolite profiles changed due to treatment with LPS but the biochemical mechanism beyond this effect is not clear. Results concernig metabolic profiles though fully convincing, should be interpreted cautiously as the procedure of cell transfection itself is a cause of some effects (compare Figs. 5 and Fig. 12 left column and Fig. 9 A). Nevertheless, the effect of the NNMT gene silencing itself on metabolite profile is still visible (Fig. 12 column C). Keeping in mind effects of LPS on p-AMPK/AMPK ratio in the control cells (Fig. 7) we also tested impact of LPS on the same parameter in HAECs with silenced NNMT-encoding gene (Fig. 13)

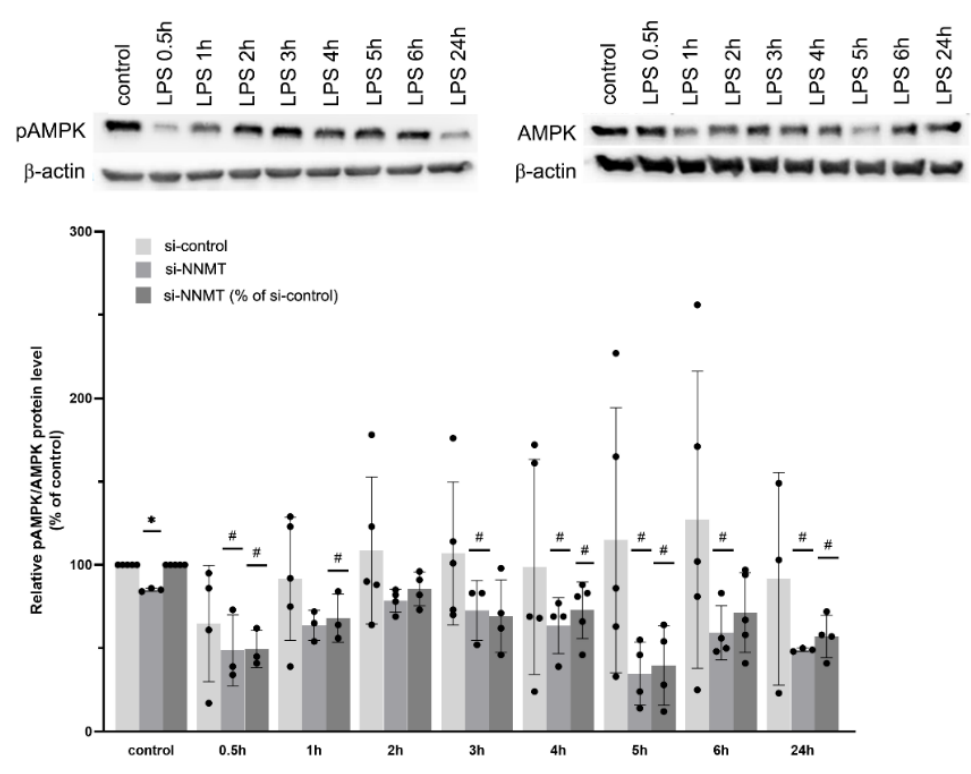

Fig.14 Effect of LPS on AMPK phosphorylation in HAECs with silenced NNMT gene. Each bar indicates mean values $\pm S . D$ of the relative change of tested parameter vs. untreated control cells assumed as 100\%. $n=3$, *p<0.05; \#p<0.05. Above the graph, corresponding western blots from the representative experiments are shown.

Interestingly, silencing of the NNMT gene counteracts LPS-induced elevation of pAMPK/AMPK ratio (Fig. 14). However, it is not accompanied by a complete restoration of calcium signalling to the level observed in cels with unaffected NNMT gene expression. It suggests that changes accompanying and somehow related to the elevation of the NNMT level are presumably not tightly coupled with aberrant calcium homeostasis observed upon LPS treatment. (Fig. 15). 


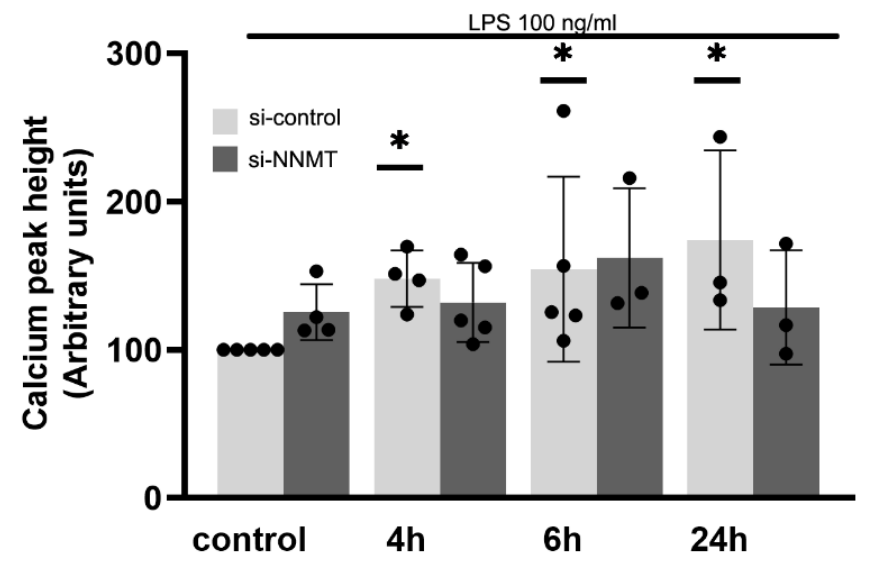

Fig. 15. Effect of LPS on thapsigargin-induced calcium response in HAEC cells in cells treated with scrambled RNA and afterthe silencing of NNMT gene. $n=3-5,{ }^{*} p<0.05$.

\section{Discussion}

Effects of LPS on endothelial physiology, inflammatory response and NO generation have been broadly discussed for a long time [Chao et al., 2017; Dauphinee et al., 2006; Dayang et al., 2019; Li et al., 2017; You et al., 2021]. However, a detailed understanding of biochemical processes particularly focused on energy metabolism in human endothelium upon treatment with LPS needs further study. This issue seems to be particularly interesting in view of the fact that bacterial liposaccharide substantially affects endothelial signal transduction which is behind physiological responses of endothelial cells to a variety of stimuli. Calcium homeostasis and proper energy metabolism are mutually dependent factors that are of high importance for all cell types but endothelial ones have relatively poorly been characterized in this matter. LPS was found to induce FADD-mediated endothelial cells apoptosis [Choi et al., 1998] and many studies are focused on harmful effects of lipopolysaccharide in endothelial cells leading to reduced viability [Chen and Song, 2020]. Moreover LPS-induced and TOllike4 receptor mediated signalling in endothelial cells has been broadly investigated [Dauphinee and Karsan, ,2006)]. However experimental efforts were focused of searching for potential therapeutic approaches to prevent sepsis and serious cardiovascular complications.

In the present study, we have investigated the effects of more gentle treatment of cells with lipopolysaccharide to follow adaptive response without affected cell viability. Thus, to minimalize potential side effects of LPS in all experiments presented here this stimulus was used at the lowest concentration and applied for the period which were established experimentally to be sufficient to elevate adhesive molecules protein level but not reduce cell survival.

\section{LPS affects endothelial bioenergetics}

Mitochondria in endothelial cells are not in the centre of ATP generation but their role as a hub of cellular calcium signalling in all mammalian cells is unquestionable [Szewczyk et al., 2015]. An increased level of proteins involved in an oxidative stress response together with substantially but reversibly changed architecture of the mitochondrial network indicate 
mitochondrial involvement in the response of HAECs to LPS. Similar effects we have previously observed in EA.hy926 cells stimulated with TNFo [Drabarek et al., 2012; Dymkowska et al., 2019]. A pattern of the time-dependent effects of LPS on metabolite profile changes and indicates a reversible inhibition of pyruvate kinase, the enzyme that controls an intensity of PEP utilization for pyruvate formation. While the first phase of the changes (reduced PEP level) does not have a clear explanation, faster generation of pyruvate is in line with LPS-induced elevation of PKM2 (Pyruvate kinase isoform) activity that was observed in macrophages exposed to lipopolysaccharide for $24 \mathrm{~h}$ [Palsson-McDermott et al., 2015]. These effects are accompanied by substantially elevated levels of Krebs cycle intermediates probably potentiated due to inhibited mitochondrial NADH reoxidation. Increased level of lactate confirms a rise in anaerobic processes which allow cells to restore the pool of $\mathrm{NAD}^{+}$. Reduced oxidative metabolism and stimulation of glycolysis were previously described for various experimental models of inflammation [Robb et al., 2020; Vijayan et al., 2019; Yarbro et al., 2019]. Relatively stable or only slightly reduced level of ATP indicates that the cellular bioenergetics despite its shift towards more glycolytic mode remains sufficient. On the other hand, some elevation in the AMP content might suggest activation of AMPK. The latter assumption is additionally strengthened as a proportion of phosphorylated form of ACC is increased in LPS-treated HAECs. A putative mechanism that is behind reduced oxidative phosphorylation seems to be not clear [Kelly and O'Neill, 2015]. Moderately increased cytosolic $\mathrm{Ca}^{2+}$ concentration should accelerate mitochondrial energy processes by stimulation of the TCA cycle. However, inhibition of the respiratory chain may have a superior effect and secondarily inhibits down-stream metabolic processes delivering reduced nucleotides (NADH and FADH2) such as the TCA cycle. Thus glycolysis is a metabolic valve that allows cells to produce ATP in a mitochondria-independent manner.

It cannot also be excluded that changes in the intensity of cellular calcium response are secondary and attributed to the reorganized mitochondrial network architecture and therefore affected ability of mitochondria to buffer cytosolic $\mathrm{Ca}^{2+}$. Transient increase in ACC phosphorylation shown in Fig. 7 reflects transient activation of AMPK and corresponds with the time course of changes in cellular lactate content. Interestingly elevated activity of AMPK was implicated as a one of factors in a down-regulation of glycolysis in vascular endothelial cells subjected to a pulsatile sher-stress [Han et al., 2021]. However, in our stable experiment sher-stress was not considered. On the other hand AMPK was found to indirectly induce PDK4 gene expression thereby inhibiting pyruvate dehydrogenase activity. [Fritzen et al., 2015]. In contrast AMPK was found to activate PDHc through phosphorylating catalytic subunit PDHA which alleviates inhibitory phosphorylation catalyed by PDKa. It stimulates TCA cycle as was observed in metastatic cancer cells [Cai et al., 2020] and is not in line with data presented in this study. It seems that AMPK interacts with several and sometime counteracting processes so the resultant, tissue-specific effect reflects precisely regulated and changing metabolic balance.

Cellular concentration of crucial metabolic factors has a key role in proper metabolic regulation and coordination of multiple metabolic processes and may switch meteboloc processes from one mode to another. One of such factors is $\mathrm{NAD}^{+}$, a broadly used electron and proton acceptor in many intracellular redox reactions. Its reduced form (NADH) is oxidized in 
the respiratory chain which is a major energy transducing process in aerobic organisms (excluding photosynthesis in plants and other autotrophs). Moreover, $\mathrm{NAD}^{+}$is used as a cofactor for sirtuins which are crucial metabolic regulators in mammals. Therefore, the cellular concentration of $\mathrm{NAD}^{+}$must be controlled and maintained at an appropriate level. This in turn implies that excessive consumption of $\mathrm{NAD}^{+}$precursors by alternative processes may be a limiting factor for $\mathrm{NAD}^{+}$formation. Recently a great attention has been focused on nicotinamide methylation catalyzed by nicotinamide N-methyltransferase (NNMT). This reaction competes for nicotinamide with NAMPT, nicotinamide phosphoribosyltransferase and potentially may limit $\mathrm{NAD}^{+}$synthesis. Moreover, nicotinamide methylation needs a methyl group donor that is S-adenosyl methionine (SAM). Therefore, an elevated NNMT activity may also affect other SAM-mediated methylation reactions. A growing body of evidence indicates that NNMT has a crucial regulatory function influencing not only energy metabolism but also epigenetic regulation in a variety of tissues [Sperber et al., 2015; Ulanovskaya et al., 2013; and for rev. Roberti et al., 2021]. However, the physiological role of this enzyme in vascular endothelial cells is still obscure. Experimental data concerning NNMT clearly show that cells challenged by some proinflammatory stimuli exhibit an elevated level of this protein [Dymkowska et al., 2021]. This may suggest that NNMT may play a role in the adaptive stress response of cells. On the other hand, its activation may contribute to the cellular harmful processes in stressful conditions. In fact, an elevated NNMT level was found in a course of some pathologies including hepatocellular carcinoma, breast cancerand stroma of colorectal cancer [Eckert et al., 2019; Li et al., 2019; Yang et al., 2021; Wang et al., 2019].

Here we have observed a time-dependent elevation of NNMT protein level in cells treated with LPS. However, we have not confirmed an expected elevation of MNA level (see Fig. $10 \mathrm{C}$ the first bars in each time point). In contrast, it was substantially reduced as soon as 30 min after addition of LPS to the growth medium and though gradually increased together with increasing NNMT level, however, it never reached the control value found in cells untreated with LPS. It suggest additional effects of lipopolysaccharide attenuating an activity of NNMT-catalysed reaction. Moreover, we have not found any differences in $\mathrm{NAD}^{+}$level in comparison to control cells regardless of the time of treatment with LPS (data not shown). Maybe $\mathrm{NAD}^{+}$synthesis in HAECs occurs through alternative pathways, thus changes in ncotinamide level have not any impact of this process [Covarrubias et al., 2021; Liu et al., 2018].

\section{Silencing of NNMT-encoding gene prevents LPS-evoked effects}

The direct link between LPS-evoked elevation of NNMT content and changes in the mitochondrial organization seems to be ambiguous. LPS only transiently affects mitochondrial network architecture which coincides with substantial changes in the NNMT level (see Fig. 4) and recoveries after prolonged treatment (see. Fig. 3). On the other hand, however, silencing of NNMT encoding gene and therefore substantial reduction of NNMT protein level protects the mitochondrial network from LPS-induced reorganization. This discrepancy may suggest that the LPS-evoked effect on the NNMT level is not a direct cause of changes in the mitochondrial network distribution within cells but a reduction of NNMT level prior to stimulation of cells with LPS somehow prevents its detrimental effect. On a basis of the presented data, it is difficult 
to conclude the mechanism behind a protective effect of NNMT gene silencing on the metabolic activity of HAEC cells treated with LPS. Interestingly silencing of the NNMT gene itself does not influence the level of metabolites but fumarate which concentration was substantially reduced. It could result from increased methylation of SDH gene promoter and reduced SDH transcription rate [Aggarwal et al., 2021, and for rev. Hawkins et al., 2018]. However, this assumption requires further experiments to test whether a decrease in the NNMT activity is accompanied by an increased s-adenosylmethionine concentration. Silencing of the NNMT gene tuned out to be very efficient (at least $60 \%$ reduction of the protein level) and reproducible. However it needed a prolonged incubation with siRNA, thus we were conscious of these risks that it can activate cellular response prior to addition of LPS.

To conclude, the aforementioned results are not sufficient to coherently explain the link between LPS-induced effects in HAECs and NNMT activity. One could speculate that aberrant $\mathrm{Ca}^{2+}$ homeostasis may be involved but still, it needs additional experimental confirmation. Recently (Qiu et al. 2021) a mechanism behind activation of SOCE in HUVEC cells treated with LPS has been precisely described. Experiments shown here fully confirm those data showing substantially increased calcium response of HAEC cells exposed to LPS upon SOCE activation with thapsigargin. The novelty of results presented here comes from the fact that silencing of the NNMT encoding gene restores normal calcium response completely abolishing effect of LPS. It is worthy of notice that all effects of LPS we have observed are substantially prevented if the NNMT-encoding gene was silenced. We assume that restoration of calcium signalling is in the bottom of remaining effects of NNMT elimination. However this tempting speculation needs deeper study to be justified or rejected.

It seems to be clear that silencing of the NNMT encoding gene and therefore reduction of the NNMT protein content and activity influences HAECs in a metabolic point(s) located "above" several important regulatory phenomena such as AMPK activation, calcium response and rearrangement of mitochondrial network architecture and some other not shown here as exceeding the scope of the presented study. Thus, regulation of NNMT activity is of paramount importance for crucial metabolic processes in endothelial cells, which outreach earlier accepted the vasculoprotective role of this enzyme by delivering MNA [Fedorowicz et al., 2016; Przyborowski et al., 2015]. Because of the fact that NNMT stands at the crossroads of metabolic pathways and epigenetic regulatory processes the complete understanding of its role not only in the endothelial cells but also in many others sems to be very difficult and requiring multilateral approaches. It is tempting to speculate that NNMT could be considered as a potential therapeutic target and this aspect was also pointed out by others [Gao et al., 2021]. However, the manifold functions of this enzyme must be cerefully counted.

\section{Acknowledgements}

We thank Prof. Stefan Chłopicki from JCET (Jagiellonian University,Cracow) for inspiring discussions and our colleague Dr. Adam Jagielski from the Institute of Biochemistry, Faculty of Biology at the University of Warsaw for assistance in metabolite measurements. 


\section{FUNDING INFORMATION}

This work was supported by the National Science Centre Poland, grant number 015/19/B/NZ3/02302.

\section{References:}

1. Aggarwal RK, Luchtel RA, Machha V, et al. Functional succinate dehydrogenase deficiency is a common adverse feature of clear cell renal cancer. Proc Natl Acad Sci U S A. 2021;118(39):e2106947118. doi:10.1073/pnas.2106947118

2. Akar S, Harmankaya İ, Uğraş S, Çelik Ç. Expression and Clinical Significance of Nicotinamide N-Methyltransferase in Cervical Squamous Cell Carcinoma. Int J Gynecol Pathol. 2020 May;39(3):289-295. doi: 10.1097/PGP.0000000000000605.

3. Bartuś M, Łomnicka M, Kostogrys RB, Kaźmierczak P, Watała C, Słominska EM, Smoleński RT, Pisulewski PM, Adamus J, Gebicki J, Chlopicki S. 1Methylnicotinamide (MNA) prevents endothelial dysfunction in hypertriglyceridemic and diabetic rats. Pharmacol Rep. 2008 Jan-Feb;60(1):127-38.

4. Begum MK, Konja D, Singhn S, Chlopicki S, Wang Y. Endothelial SIRT1 as a Target for the Prevention of Arterial Aging: Promises and Challenges. J. Cardiovasc. Pharmacol. 2021;00:1-15.

5. Bertani B, Ruiz N. Function and Biogenesis of Lipopolysaccharides. EcoSal Plus. 2018;8(1):10.1128/ecosalplus.ESP-0001-2018. doi:10.1128/ecosalplus.ESP-00012018

6. Cai Z, Li CF, Han F, Liu C, Zhang A, Hsu CC, Peng D, Zhang X, Jin G, Rezaeian AH, Wang G, Zhang W, Pan BS, Wang CY, Wang YH, Wu SY, Yang SC, Hsu FC, D'Agostino RB Jr, Furdui CM, Kucera GL, Parks JS, Chilton FH, Huang CY, Tsai FJ, Pasche B, Watabe K, Lin HK. Phosphorylation of PDHA by AMPK Drives TCA Cycle to Promote Cancer Metastasis. Mol Cell. 2020 Oct 15;80(2):263-278.e7. doi: 10.1016/j.molcel.2020.09.018.

7. Campagna R, Mateuszuk Ł, Wojnar-Lason K, Kaczara P, Tworzydło A, Kij A, Bujok R, Mlynarski J, Wang Y, Sartini D, Emanuelli M, Chlopicki S. Nicotinamide $\mathrm{N}$-methyltransferase in endothelium protects against oxidant stress-induced endothelial injury. Biochim Biophys Acta Mol Cell Res. 2021 Sep;1868(10):119082. doi: 10.1016/j.bbamcr.2021.119082. Epub 2021 Jun 19. PMID: 34153425.

8. Chang CY, Tucci M, Baker RC. Lipopolysaccharide-stimulated nitric oxide production and inhibition of cell proliferation is antagonized by ethanol in a clonal macrophage cell line. Alcohol. 2000 Jan;20(1):37-43. doi: 10.1016/s07418329(99)00054-3.

9. Chao HH, Chen PY, Hao WR, Chiang WP, Cheng TH, Loh SH, Leung YM, Liu JC, Chen JJ, Sung LC. Lipopolysaccharide pretreatment increases protease-activated receptor-2 expression and monocyte chemoattractant protein-1 secretion in vascular endothelial cells. J Biomed Sci. 2017 Nov 15;24(1):85. doi: 10.1186/s12929-0170393-1. 
10. Chen X, Song D. LPS promotes the progression of sepsis by activation of lncRNA HULC/miR-204-5p/TRPM7 network in HUVECs. Biosci Rep. 2020 Jun 26;40(6):BSR20200740. doi: 10.1042/BSR20200740.

11. Chlopicki S, Swies J, Mogielnicki A, Buczko W, Bartus M, Lomnicka M, Adamus J, Gebicki J. 1-Methylnicotinamide (MNA), a primary metabolite of nicotinamide, exerts anti-thrombotic activity mediated by a cyclooxygenase-2/prostacyclin pathway. Br J Pharmacol. 2007 Sep;152(2):230-9. doi: 10.1038/sj.bjp.0707383.

12. Choi KB, Wong F, Harlan JM, Chaudhary PM, Hood L, Karsan A. Lipopolysaccharide mediates endothelial apoptosis by a FADD-dependent pathway. J Biol Chem. 1998 Aug 7;273(32):20185-8. doi: 10.1074/jbc.273.32.20185.

13. Covarrubias AJ, Perrone R, Grozio A, Verdin E. NAD+ metabolism and its roles in cellular processes during ageing. Nat Rev Mol Cell Biol. 2021;22(2):119-141. doi:10.1038/s41580-020-00313-x

14. Dauphinee SM, Karsan A. Lipopolysaccharide signaling in endothelial cells. Lab Invest. 2006 Jan;86(1):9-22. doi: 10.1038/labinvest.3700366.

15. Dayang EZ, Plantinga J, Ter Ellen B, van Meurs M, Molema G, Moser J. Identification of LPS-Activated Endothelial Subpopulations With Distinct Inflammatory Phenotypes and Regulatory Signaling Mechanisms. Front Immunol. 2019 May 24;10:1169. doi: 10.3389/fimmu.2019.01169.

16. Drabarek B, Dymkowska D, Szczepanowska J, Zabłocki K. TNF $\alpha$ affects energy metabolism and stimulates biogenesis of mitochondria in EA.hy926 endothelial cells. Int J Biochem Cell Biol. 2012 Sep;44(9):1390-7. doi: 10.1016/j.biocel.2012.05.022.

17. Dymkowska D, Drabarek B, Michalik A, Nowak N, Zabłocki K. TNF $\alpha$ stimulates NO release in EA.hy926 cells by activating the CaMKK $\beta$-AMPK-eNOS pathway. Int J Biochem Cell Biol. 2019 Jan;106:57-67. doi: 10.1016/j.biocel.2018.11.010.

18. Dymkowska D, Drabarek B, Podszywałow-Bartnicka P, Szczepanowska J, Zabłocki K. Hyperglycaemia modifies energy metabolism and reactive oxygen species formation in endothelial cells in vitro. Arch Biochem Biophys. 2014 Jan 15;542:713. doi: 10.1016/j.abb.2013.11.008.

19. Dymkowska D, Kawalec M, Wyszomirski T, Zabłocki K. Mild palmitate treatment increases mitochondrial mass but does not affect EA.hy926 endothelial cells viability. Arch Biochem Biophys. 2017 Nov 15;634:88-95. doi: 10.1016/j.abb.2017.10.006.

20. Dymkowska D, Wrzosek A, Zabłocki K. Atorvastatin and pravastatin stimulate nitric oxide and reactive oxygen species generation, affect mitochondrial network architecture and elevate nicotinamide $\mathrm{N}$-methyltransferase level in endothelial cells. J Appl Toxicol. 2021 Jul;41(7):1076-1088. doi: 10.1002/jat.4094.

21. Eckert MA, Coscia F, Chryplewicz A, et al. Proteomics reveals NNMT as a master metabolic regulator of cancer-associated fibroblasts. Nature. 2019;569(7758):723728. doi:10.1038/s41586-019-1173-8.

22. Emanuelli M, Santarelli A, Sartini D, Ciavarella D, Rossi V, Pozzi V, Rubini C, Lo Muzio L. Nicotinamide N-Methyltransferase upregulation correlates with tumour 
differentiation in oral squamous cell carcinoma. Histol Histopathol. 2010 Jan;25(1):15-20. doi: 10.14670/HH-25.15.

23. Farhana A, Khan YS. Biochemistry, Lipopolysaccharide. [Updated 2021 Apr 29]. In: StatPearls [Internet]. Treasure Island (FL): StatPearls Publishing; 2021 Jan-. Available from: https://www.ncbi.nlm.nih.gov/books/NBK554414/

24. Fedorowicz A, Mateuszuk $€$, Kopec G, et al. Activation of the nicotinamide Nmethyltransferase (NNMT)-1-methylnicotinamide (MNA) pathway in pulmonary hypertension. Respir Res. 2016;17(1):108. Published 2016 Aug 31. doi:10.1186/s12931-016-0423-7

25. Fock EM, Parnova RG. Protective Effect of Mitochondria-Targeted Antioxidants against Inflammatory Response to Lipopolysaccharide Challenge: A Review. Pharmaceutics. 2021 Jan 22;13(2):144. doi: 10.3390/pharmaceutics13020144.

26. Fritzen AM, Lundsgaard AM, Jeppesen J, Christiansen ML, Biensø R, Dyck JR, Pilegaard H, Kiens B. 5'-AMP activated protein kinase $\alpha 2$ controls substrate metabolism during post-exercise recovery via regulation of pyruvate dehydrogenase kinase 4. J Physiol. 2015 Nov 1;593(21):4765-80. doi: 10.1113/JP270821.

27. Gabarin RS, Li M, Zimmel PA, Marshall JC, Li Y, Zhang H. Intracellular and Extracellular Lipopolysaccharide Signaling in Sepsis: Avenues for Novel Therapeutic Strategies. J Innate Immun. 2021;13(6):323-332. doi: $10.1159 / 000515740$.

28. Gao Y, Martin NI, van Haren MJ. Nicotinamide N-methyl transferase (NNMT): An emerging therapeutic target. Drug Discov Today. 2021 Nov;26(11):2699-2706. doi: 10.1016/j.drudis.2021.05.011.

29. Han Y, He M, Marin T, Shen H, Wang WT, Lee TY, Hong HC, Jiang ZL, Garland T Jr, Shyy JY, Gongol B, Chien S. Roles of KLF4 and AMPK in the inhibition of glycolysis by pulsatile shear stress in endothelial cells. Proc Natl Acad Sci U S A. 2021 May 25;118(21):e2103982118. doi: 10.1073/pnas.2103982118.

30. Hawkins LJ, Al-Attar R, Storey KB. Transcriptional regulation of metabolism in disease: From transcription factors to epigenetics. PeerJ. 2018;6:e5062. Published 2018 Jun 15. doi:10.7717/peerj.5062

31. Kelly B, O'Neill LA. Metabolic reprogramming in macrophages and dendritic cells in innate immunity. Cell Res. 2015 Jul;25(7):771-84. doi: 10.1038/cr.2015.68.

32. Kim HC, Mofarrahi M, Vassilakopoulos T, Maltais F, Sigala I, Debigare R, Bellenis I, Hussain SN. Expression and functional significance of nicotinamide N-methyl transferase in skeletal muscles of patients with chronic obstructive pulmonary disease. Am J Respir Crit Care Med. 2010 Apr 15;181(8):797-805. doi: 10.1164/rccm.200906-0936OC.

33. Laemmli UK. Cleavage of structural proteins during the assembly of the head of bacteriophage T4. Nature. 1970 Aug 15;227(5259):680-5. doi: 10.1038/227680a0.

34. Li J, You S, Zhang S, et al. Elevated N-methyltransferase expression induced by hepatic stellate cells contributes to the metastasis of hepatocellular carcinoma via regulation of the CD44v3 isoform. Mol Oncol. 2019;13(9):1993-2009. doi:10.1002/1878-0261.12544 
35. Li YY, Zhang GY, He JP, Zhang DD, Kong XX, Yuan HM, Chen FL. Ufm1 inhibits LPS-induced endothelial cell inflammatory responses through the NF- $\kappa \mathrm{B}$ signaling pathway. Int J Mol Med. 2017 May;39(5):1119-1126. doi: 10.3892/ijmm.2017.2947.

36. Liu L, Su X, Quinn WJ 3rd, et al. Quantitative Analysis of NAD SynthesisBreakdown Fluxes. Cell Metab. 2018;27(5):1067-1080.e5. doi:10.1016/j.cmet.2018.03.018

37. Mateuszuk Ł, Campagna R, Kutryb-Zając B, et al. Reversal of endothelial dysfunction by nicotinamide mononucleotide via extracellular conversion to nicotinamide riboside. Biochem Pharmacol. 2020;178: 114019-114030

38. Menden H, Tate E, Hogg N, Sampath V. LPS-mediated endothelial activation in pulmonary endothelial cells: role of Nox2-dependent IKK- $\beta$ phosphorylation. Am J Physiol Lung Cell Mol Physiol. 2013 Mar 15;304(6):L445-55. doi: 10.1152/ajplung.00261.2012.

39. Meng F, Lowell CA. Lipopolysaccharide (LPS)-induced macrophage activation and signal transduction in the absence of Src-family kinases Hck, Fgr, and Lyn. J Exp Med. 1997 May 5;185(9):1661-70. doi: 10.1084/jem.185.9.1661.

40. Mistry RJ, Klamt F, Ramsden DB, Parsons RB. Nicotinamide N-methyltransferase expression in SH-SY5Y human neuroblastoma cells decreases oxidative stress. J Biochem Mol Toxicol. 2020 Mar;34(3):e22439. doi: 10.1002/jbt.22439.

41. Nejabati HR, Mihanfar A, Pezeshkian M, Fattahi A, Latifi Z, Safaie N, Valiloo M, Jodati AR, Nouri M. N1-methylnicotinamide (MNAM) as a guardian of cardiovascular system. J Cell Physiol. 2018 Oct;233(10):6386-6394. doi: 10.1002/jcp.26636.

42. Palsson-McDermott EM, Curtis AM, Goel G, Lauterbach MA, Sheedy FJ, Gleeson LE, van den Bosch MW, Quinn SR, Domingo-Fernandez R, Johnston DG, Jiang JK, Israelsen WJ, Keane J, Thomas C, Clish C, Vander Heiden M, Xavier RJ, O'Neill LA. Pyruvate kinase M2 regulates Hif- $1 \alpha$ activity and IL- $1 \beta$ induction and is a critical determinant of the warburg effect in LPS-activated macrophages. Cell Metab. 2015 Jan 6;21(1):65-80. doi: 10.1016/j.cmet.2014.12.005.

43. Przyborowski K, Wojewoda M, Sitek B, et al. Effects of 1-Methylnicotinamide (MNA) on Exercise Capacity and Endothelial Response in Diabetic Mice. PLoS One. 2015;10(6):e0130908. Published 2015 Jun 26. doi:10.1371/journal.pone.0130908

44. Qiu X, Liang X, Li H, Sun R. LPS-induced vein endothelial cell injury and acute lung injury have Btk and Orai 1 to regulate SOC-mediated calcium influx. International Immunopharmacology,Volume 90, 2021, 107039, https://doi.org/10.1016/j.intimp.2020.107039

45. Robb JL, Hammad NA, Weightman Potter PG, Chilton JK, Beall C, Ellacott KLJ. The metabolic response to inflammation in astrocytes is regulated by nuclear factorkappa B signaling. Glia. 2020 Nov;68(11):2246-2263. doi: 10.1002/glia.23835.

46. Roberti A, Fernández AF, Fraga MF. Nicotinamide N-methyltransferase: At the crossroads between cellular metabolism and epigenetic regulation. Mol Metab. 2021 Mar;45:101165. doi: 10.1016/j.molmet.2021.101165. 
47. Roessler M, Rollinger W, Palme S, Hagmann ML, Berndt P, Engel AM, Schneidinger B, Pfeffer M, Andres H, Karl J, Bodenmüller H, Rüschoff J, Henkel T, Rohr G, Rossol S, Rösch W, Langen H, Zolg W, Tacke M. Identification of nicotinamide $\mathrm{N}$-methyltransferase as a novel serum tumor marker for colorectal cancer. Clin Cancer Res. 2005 Sep 15;11(18):6550-7. doi: 10.1158/10780432.CCR-05-0983.

48. Sampath V, Radish AC, Eis AL, Broniowska K, Hogg N, Konduri GG. Attenuation of lipopolysaccharide-induced oxidative stress and apoptosis in fetal pulmonary artery endothelial cells by hypoxia. Free Radic Biol Med. 2009 Mar 1;46(5):663-71. doi: 10.1016/j.freeradbiomed.2008.12.008.

49. Schlegel N, Baumer Y, Drenckhahn D, Waschke J. Lipopolysaccharide-induced endothelial barrier breakdown is cyclic adenosine monophosphate dependent in vivo and in vitro. Crit Care Med. 2009 May;37(5):1735-43. doi: 10.1097/CCM.0b013e31819deb6a.

50. Sperber H, Mathieu J, Wang Y, Ferreccio A, Hesson J, Xu Z, Fischer KA, Devi A, Detraux D, Gu H, Battle SL, Showalter M, Valensisi C, Bielas JH, Ericson NG, Margaretha L, Robitaille AM, Margineantu D, Fiehn O, Hockenbery D, Blau CA, Raftery D, Margolin AA, Hawkins RD, Moon RT, Ware CB, Ruohola-Baker H. The metabolome regulates the epigenetic landscape during naive-to-primed human embryonic stem cell transition. Nat Cell Biol. 2015 Dec;17(12):1523-35. doi: $10.1038 / \mathrm{ncb} 3264$.

51. Sternak M, Khomich TI, Jakubowski A, Szafarz M, Szczepański W, Białas M, Stojak M, Szymura-Oleksiak J, Chłopicki S. Nicotinamide N-methyltransferase (NNMT) and 1-methylnicotinamide (MNA) in experimental hepatitis induced by concanavalin A in the mouse. Pharmacol Rep. 2010 May-Jun;62(3):483-93. doi: 10.1016/s1734-1140(10)70304-2.

52. Szewczyk A, Wiesława Jarmuszkiewicz, Agnieszka Kozieł, Izabela Sobieraj, Agnieszka Łukasiak, Agata Skup, Piotr Bednarczyk, Beata Drabarek, Dorota Dymkowska, Antoni Wrzosek, Krzysztof Zabłocki (2015) Mitochondrial mechanisms of endothelial dysfunction. Pharm. Rep. 67: 704-710; doi: 10.1016/j.pharep.2015.04.009.

53. Tomida M, Ohtake H, Yokota T, Kobayashi Y, Kurosumi M. Stat3 up-regulates expression of nicotinamide $\mathrm{N}$-methyltransferase in human cancer cells. J Cancer Res Clin Oncol. 2008 May;134(5):551-9. doi: 10.1007/s00432-007-0318-6.

54. Ulanovskaya OA, Zuhl AM, Cravatt BF. NNMT promotes epigenetic remodeling in cancer by creating a metabolic methylation sink. Nat Chem Biol. 2013 May;9(5):300-6. doi: 10.1038/nchembio.1204. Epub 2013 Mar 3. PMID: 23455543; PMCID: PMC3631284.

55. Vijayan V, Pradhan P, Braud L, Fuchs HR, Gueler F, Motterlini R, Foresti R, Immenschuh S. Human and murine macrophages exhibit differential metabolic responses to lipopolysaccharide - A divergent role for glycolysis. Redox Biol. 2019 Apr;22:101147. doi: 10.1016/j.redox.2019.101147. 
56. Wang $\mathrm{Y}$, Zeng $\mathrm{J}, \mathrm{Wu} \mathrm{W}$, et al. Nicotinamide $\mathrm{N}$-methyltransferase enhances chemoresistance in breast cancer through SIRT1 protein stabilization. Breast Cancer Res. 2019;21(1):64. Published 2019 May 17. doi:10.1186/s 13058-019-1150-z

57. Whitfield C, Williams DM, Kelly SD. Lipopolysaccharide O-antigens-bacterial glycans made to measure. J Biol Chem. 2020 Jul 31;295(31):10593-10609. doi: 10.1074/jbc.REV120.009402.

58. Yang J, Tong Q, Zhang Y, et al. Overexpression of Nicotinamide Nmethyltransferase mainly covers stroma of colorectal cancer and correlates with unfavorable survival by its product 1-MNA. J Cancer. 2021;12(20):6170-6181. Published 2021 Aug 26. doi:10.7150/jca.56419

59. Yarbro JR, Pence BD. Classical monocytes from older adults maintain capacity for metabolic compensation during glucose deprivation and lipopolysaccharide stimulation. Mech Ageing Dev. 2019 Oct;183:111146. doi: 10.1016/j.mad.2019.111146.

60. Yoshino J, Imai S. Accurate measurement of nicotinamide adenine dinucleotide $\left(\mathrm{NAD}^{+}\right)$with high-performance liquid chromatography. Methods Mol Biol. 2013;1077:203-15. doi: 10.1007/978-1-62703-637-5_14.

61. You L, Zhang D, Geng H, Sun F, Lei M. Salidroside protects endothelial cells against LPS-induced inflammatory injury by inhibiting NLRP3 and enhancing autophagy. BMC Complement Med Ther. 2021 May 19;21(1):146. doi: 10.1186/s12906-021-03307-0.

62. Zabłocki K, Szczepanowska J, Duszyński J. Extracellular pH modifies mitochondrial control of capacitative calcium entry in Jurkat cells. J Biol Chem. 2005 Feb 4;280(5):3516-21. doi: 10.1074/jbc.M411507200. 